\title{
EFEITO DO ENRIQUECIMENTO DE BISCOITOS TIPO ÁGUA E SAL, COM EXTRATO DE LEVEDURA (Saccharomyces sp.) ${ }^{1}$
}

\author{
Marjorie Carelli Costa SANTUCCI², Izabela Dutra ALVIM², Eliete Vaz de FARIA², \\ Valdemiro Carlos SGARBIERI ${ }^{2, *}$
}

\section{RESUMO}

Os objetivos desta pesquisa foram a caracterização química de um autolisado (AT) de levedura (Saccharomyces sp. ), subproduto da fermentação alcoólica e de seus derivados, fração solúvel (Ex) e insolúvel (FI). O autolisado integral (AT) e o extrato (Ex), depois de desidratados por atomização (spray dryer) foram utilizados como enriquecedores do gosto e do aroma de biscoitos salgados do tipo água e sal. A adição ao biscoito de $5 \%$ de Ex elevou o escore de aminoácidos essenciais (EAE) de $38 \%$ para $60 \%$ e o índice de utilização líquida da proteina (NPR) de 1,0 para 2,0 (100\%). Houve ainda uma melhora significativa na aceitabilidade e na preferência dos biscoitos enriquecidos, pelos consumidores.

Palavras-chave: levedura; derivados; ingrediente; biscoito; formulação.

\section{SUMMARY}

EFFECT OF ENRICHMENT OF WATER AND SALT BISCUITS WITH YEAST (Saccharomyces sp. ) EXTRACT. The objective of this investigation was to establish the composition of the yeast (Saccharomyces sp. ) obtained as a byproduct of the alcoholic fermentation industry, in the form of an autolysate (AT) and their derivatives, extract (Ex) and insoluble fraction (FI). The total autolysate (AT) and the extract (Ex), after dehydration in spray dryer, were utilized as flavour enhancers in salted biscuits. Addition to the biscuits of $5 \%$ Ex improved the essential amino acid score (EAE) from 38 to $60 \%$, and the net protein utilization index (NPR) from 1.0 to 2.0 (100\%). There was also a significant improvement in the acceptability and preference of the enriched biscuits by the consumers.

Keywords: yeast; derivative; ingredient; biscuit; formulation.

\section{1 - INTRODUÇÃO}

Derivados de levedura são usados em alimentação humana como suplemento nutricional, flavorizante e espessante [1, 9].

A utilização de leveduras como suplemento nutricional se deve principalmente a sua composição: proteina 31 a 48\%; elevados teores de vitaminas, especialmente do complexo $\mathrm{B}\left(\mathrm{B}_{1}, \mathrm{~B}_{2}, \mathrm{~B}_{6}\right.$, niacina, ácido pantotênico, ácido fólico e biotina); minerais, incluindo macroelementos $(\mathrm{Ca}$, $\mathrm{P}, \mathrm{Mg}, \mathrm{K}, \mathrm{Na}, \mathrm{Al}$ e $\mathrm{Fe}$ ) e microelementos ( $\mathrm{Mn}, \mathrm{Cu}, \mathrm{B}, \mathrm{Zn}$, $\mathrm{Mo}, \mathrm{Cd}, \mathrm{Cr}, \mathrm{Ni}, \mathrm{Pb}, \mathrm{Si}$ e $\mathrm{Se})$; carboidratos entre $25-35 \%$ [11].

Os principais derivados de levedura são os autolisados produzidos pela autodigestão das células, extrato de levedura e parede celular de levedura, frações obtidas por centrifugação do autolisado [17]. O extrato de levedura contém todo o material solúvel do autolisado, incluindo proteínas, peptídios, aminoácidos livres, nucleotídeos, vitaminas, oligossacarídeos e minerais $[11,17]$. A fração insolúvel, composta principalmente de parede celular é rica em manoproteinas, $\beta$-glicana e manana. Tanto manana como glicana, quando incorporadas em alimentos, funcionam como transportadores de gosto e aroma, espessantes e estabilizantes [15]. Polimeros de glicana e manana podem dar origem a oligossacarideos (OS), carboidratos com 3 a 10 monômeros de açúcares. Esses oligossacarídeos têm sido bastante estudados como ingrediente funcional, tanto em nutrição animal como humana. A principal proprie-

\footnotetext{
Recebido para publicação em 22/06/2002. Aceito para publicação em 13/05/2003 (000863).

${ }^{1}$ Instituto de Tecnologia de Alimentos (ITAL). Av. Brasil, 2880, CEP 13073001, Campinas, SP.

* A quem a correspondência deve ser enviada.
}

dade dos OS é de inibir bactérias patogênicas como Salmonella e Escherichia coli e, ao mesmo tempo, estimular o crescimento de Bifidobacterium sp., no intestino do homem e dos animais [14, 19]. Também, os oligonucleotídeos presentes nos extratos de levedura poderão desempenhar funções fisiológicas importantes como estímulo ao sistema imune, aumento na biodisponibilidade de ferro, melhoria da microflora intestinal, estimulo ao crescimento e maturação intestinal $[7,8]$.

Em ciência e tecnologia de alimentos, extratos de levedura têm sido usados para complementar ou substituir o extrato de carne ou hidrolisados de proteina vegetal, conferindo sabores e aromas que lembram os da carne, de queijo e de mostarda, dependendo da composição em aminoácidos das células e das condições do processamento $[1,11,16]$.

Neste trabalho são apresentados os efeitos da adição de extrato de levedura nas características sensoriais e nutritivas de um biscoito tradicional tipo água e sal.

\section{2 - MATERIAL E MÉTODOS}

\section{1 - Ingredientes e formulação}

Os ingredientes e suas proporções utilizadas na formulação dos biscoitos (padrão e enriquecido) são apresentados na Tabela 1. Os ingredientes utilizados foram todos de grau alimentício.

\section{2 - Produção do extrato de levedura}

Obteve-se o material de destilaria de álcool em suspensão de aproximadamente $20 \%$ de células. A suspensão inicial foi diluída com água corrente $(1: 1)$ e centrifugada em centrifuga de pratos (Alfa Laval, tipo 
BRPX 20739-S60) a 3500g e fluxo de $150 \mathrm{~kg} / \mathrm{h}$ com descargas a cada $5 \mathrm{~min}$, obtendo-se um sedimento de biomassa e um sobrenadante (água de saída). Essa água foi recirculada na centrifuga, obtendo-se uma suspensão concentrada de células que foi juntada à biomassa.

A biomassa foi desidratada em "spray dryer" (Niro Atomizer $\mathrm{CB}_{3}$ 104D) à temperatura de $180 \pm 5^{\circ} \mathrm{C}$ na entrada da câmara e $80 \pm 5^{\circ} \mathrm{C}$ na saída. A biomassa desidratada foi ressuspensa em água $(10 \% \mathrm{p} / \mathrm{v})$ e adicionada de $7 \%(\mathrm{v} / \mathrm{p})$ de etanol, $2 \%(\mathrm{p} / \mathrm{p})$ de $\mathrm{NaCl}$ e $15 \%(\mathrm{v} / \mathrm{v})$ de um pré-autolisado. A mistura foi levada para um feremntador de 250L (New Brunswick - IF 250) e mantida, sob agitação mecânica a $55^{\circ} \mathrm{C}$ por $24 \mathrm{~h}$. A autólise foi interrompida aquecendo-se $15 \mathrm{~min}$ a $85^{\circ} \mathrm{C}$.

TABELA 1. Fórmulas para o preparo dos biscoitos, padrão e enriquecidos.

\begin{tabular}{lcc}
\hline $\begin{array}{l}\text { Ingredientes } \\
\text { (gramas) }\end{array}$ & $\begin{array}{c}\text { Biscoito } \\
\text { padrão }\end{array}$ & $\begin{array}{c}\text { Biscoitos } \\
\text { enriquecidos }\end{array}$ \\
\hline Farinha de trigo & 4000 & 4000 \\
Amido de milho & 1000 & 1000 \\
Gordura hidrogenada & 900 & 900 \\
Açúcar invertido & 200 & 200 \\
Açúcar refinado & 100 & 100 \\
Extrato de malte & 100 & 100 \\
Sal & 75 & 75 \\
Bicarbonato de sódio & 30 & 30 \\
Bicarbonato de amônio & 30 & 30 \\
Ácido lático & 15 & 15 \\
Bissulfito de sódio & 1 & 1 \\
Água & 1200 & 1220 \\
Extrato de levedura & & 250 \\
Aroma de "bacon" temperado & & 75 \\
Aroma reforçado de queijo & & 37,5 \\
Aroma de ervas finas & & 57,5 \\
\hline
\end{tabular}

O autolisado foi centrifugado em centrífuga de pratos (3500g, fluxo de $150 \mathrm{~kg} / \mathrm{h}$ e descarga a cada 5 minutos), para obtenção da fração insolúvel (FI) e da fração solúvel (Ex). O extrato foi concentrado por aquecimento $\left(60^{\circ} \mathrm{C}\right.$, sob vácuo) até $20-25 \%$ de sólidos. Antes da secagem (spray dryer), adicionou-se ao extrato $25 \%$ de maltodextrina (p/ p) com base nos sólidos solúveis do Ex.

\section{3 - Processamento dos biscoitos}

Os biscoitos foram confeccionados pela mistura dos ingredientes a seco, seguindo-se a adição da água, em uma masseira (misturadeira). Seguiu-se a laminação e o corte da massa laminada. Por último, o cozimento em um forno de esteira contínua a uma temperatura inicial de $170^{\circ} \mathrm{C}$, atingindo $280^{\circ} \mathrm{C}$ nos estágios subseqüentes e caindo para $235^{\circ} \mathrm{C}$ no estágio final da secagem. O tempo de permanência real do produto no interior do forno foi de 3 minutos.

\section{4 - Métodos analíticos}

\subsection{1 - Composição centesimal}

Umidade, cinzas e proteína bruta $(\% \mathrm{~N}$ x 5,8$)$ foram determinadas segundo A.O.A.C. [2]. Lipidios totais foram determinados pelo método de BLIGH \& DYER [4]. Fibra alimentar, solúvel e insolúvel, pelo método de ASP et al. [3]. Ácido ribonucléico (RNA), pelo método de HERBERT et al. [13].

\subsection{2 - Determinação de aminoácidos}

A composição em aminoácidos foi determinada em aparelho HPLC (Dionex Dx-300) com separação em colunas de troca catiônica e reação pós-coluna com ninidrina. As amostras foram previamente submetidas à hidrólise ácida $\left(\mathrm{HCl} 6 \mathrm{~N}, 105^{\circ} \mathrm{C}, 22 \mathrm{~h}\right)$, seguindo-se a eliminação do ácido em rotavapor, sob vácuo e redissolução dos aminoácidos em tampão apropriado para a análise. A quantificação de cada aminoácido foi feita com base em mistura padrão de aminoácidos fornecida pela Pierce.

\section{5 - Avaliação sensorial}

Os biscoitos foram submetidos à avaliação sensorial por 52 consumidores (homens e mulheres), na faixa etária entre 15 e 55 anos.

Avaliou-se a preferência com relação ao sabor por meio da ordenação $(1=$ mais preferido, $4=$ menos preferido). Foi também avaliado o sabor de cada amostra, pelo uso de escala hedônica de 9 pontos $(9=$ gostei extremamente, 5 = não gostei, nem desgostei e 1 = desgostei extremamente).

Para os testes, as amostras foram apresentadas em códigos de 3 dígitos aleatórios, segundo um delineamento de blocos completos casualizados. Os testes foram conduzidos em cabines individuais, iluminadas com lâmpadas fluorescentes, sendo a coleta e a análise dos dados realizadas por um sistema computadorizado (Compusense Five), versão 3.8. Os dados de ordenação foram analisados estatisticamente com base na análise de Friedman, segundo MEILGAARD et al. [18] e o teste de Fisher para comparação entre amostras.

\section{6 - Composição e avaliação nutricional dos biscoi- tos}

A avaliação nutricional dos biscoitos foi feita com base na composição centesimal, no escore de aminoácidos essenciais (EAE) [10], no escore de aminoácidos essenciais corrigido pela digestibilidade verdadeira da proteína (PDCAAS) [12] e no NPR (quociente líquido de utilização protéica) [22].

\subsection{1 - Ensaios com ratos}

Usaram-se ratos (Ratus norvergicus), machos da linhagem Wistar com 21 dias de idade no início do experimento. Os animais foram aleatoriamente separados em grupos de 10 ratos/grupo e mantidos em gaiolas individuais, com livre acesso á água e dieta. As condições no laboratório de ensaio foram de $21 \pm 2{ }^{\circ} \mathrm{C}$ e períodos alternados de claro-escuro de 12 horas. 
As dietas foram preparadas tendo por base as recomendações do "American Institute of Nutrition" AIN93G [21] com alterações apenas para concentração de proteina de $17 \%$ para $8 \%$, completando a diferença com carboidrato. Ajustes também foram feitos para acomodar as contribuições em macronutrientes dos biscoitos.

Os tratamentos testados foram: dieta sem proteína (aprotéica); dieta com 8\% de caseína (controle); dieta com $8 \%$ de proteína fornecida pelo biscoito padrão; dieta com $8 \%$ de proteina do biscoito enriquecido.

O ensaio teve a duração de 3 semanas e os indices calculados foram: Dv\% (digestibilidade verdadeira da proteína) $=$ nitrogênio absorvido/nitrogênio ingerido, sendo que o $\mathrm{N}$ absorvido foi calculado pela diferença entre o $\mathrm{N}$ ingerido e o excretado nas fezes (já descontado o $\mathrm{N}$ das fezes do grupo em dieta aprotéica); NPR = ganho de peso (g) do grupo GI + perda de peso (g) do grupo GII/consumo de proteina do grupo GII (GI = grupo em dieta aprotéica, GII = grupo em dieta com $8 \%$ de proteína).

\section{3 - RESULTADOS E DISCUSSÃo}

A composição centesimal do autolisado integral (AT) e das frações, solúvel (Ex) e insolúvel (FI) de levedura (Saccharomyces sp. ) proveniente de destilaria de álcool, é apresentada na Tabela 2.

Observa-se que no Ex concentram-se, em relação ao AT e FI, as proteinas (50,7\%), os minerais $(11,7 \%)$ e o RNA (8,3\%). Boa parte dos minerais é representada, no Ex, pelo cloreto de sódio usado como agente plasmolizante no processo de autólise. Por outro lado, a concentração de não determinado $(25,6 \%)$, relatado para o Ex na Tabela 2, representa basicamente a maltodextrina $(25 \%)$, adicionada ao Ex, antes da secagem em "spray".

TABELA 2. Composição centesimal do autolisado integral (AT), do extrato (Ex) e da fração insolúvel (FI), em base seca.

\begin{tabular}{lccc}
$\begin{array}{l}\text { Amostra } \\
\text { (\% b.s.) }\end{array}$ & $\begin{array}{c}\text { Autolisado } \\
\text { (AT) }\end{array}$ & $\begin{array}{c}\text { Extrato } \\
\text { (Ex) }\end{array}$ & $\begin{array}{c}\text { Fração insol úvel } \\
\text { (FI) }\end{array}$ \\
\hline $\begin{array}{l}\text { Proteína (N x 5,8) } \\
\text { Fibra alimentar }\end{array}$ & 40,4 & 50,7 & 18,8 \\
$\quad$ Total & 31,2 & 3,3 & 70,8 \\
$\quad$ Solúvel & 30,4 & 3,3 & 67,0 \\
$\quad$ Insolúvel & 1,0 & 0,0 & 3,8 \\
Cinzas & 6,2 & 11,7 & 1,4 \\
Lipídios totais & 1,2 & 0,4 & 2,3 \\
Ácido ribonucléico (RNA) & 5,6 & 8,3 & 3,4 \\
Não determinado & 15,4 & 25,6 & 3,3
\end{tabular}

A fração insolúvel (FI) contém acima de $70 \%$ de fibra alimentar, predominantemente fibra solúvel (67\%) representada por poli e oligossacarideos da parede celular. Contém ainda cerca de 19\% de proteina, em que predominam proteinas estruturais como as manoproteinas [6].

A composição centesimal do biscoito (fórmula padrão) e de 3 tipos de biscoitos enriquecidos com 5\% de extrato de levedura (Ex) e diferentes saborizantes é apresentada na Tabela 3.

De um modo geral, a introdução dos ingredientes enriquecedores não modificou substancialmente a com- posição do biscoito de fórmula padrão, exceto por um pequeno aumento $(\sim 13,5 \%)$ no teor de proteina, da umidade (32 a 61\%) e uma diminuição no teor de carboidrato ( 5\%).

A densidade calórica calculada é de valor médio para os 4 tipos de biscoito, sendo que $100 \mathrm{~g}$ de qualquer dos produtos atenderiam aproximadamente $17 \%$ e $23 \%$ das necessidades calóricas de adultos jovens em atividade leve, respectivamente dos sexos masculino e feminino [20].

TABELA 3. Composição centesimal de biscoitos fórmula padrão e enriquecidos com 5\% de extrato (Ex) de levedura e 3 sabores diferentes.

\begin{tabular}{lcccc}
\multicolumn{1}{c}{$\begin{array}{c}\text { Componentes } \\
(\%)^{1}\end{array}$} & $\begin{array}{c}\text { Biscoito } \\
\text { padrão }\end{array}$ & $\begin{array}{c}\text { Biscoito 5\% Ex } \\
\text { (sabor bacon) }\end{array}$ & $\begin{array}{c}\text { Biscoito 5\% Ex } \\
\text { (sabor queijo) }\end{array}$ & $\begin{array}{c}\text { Biscoito 5\% Ex } \\
\text { (sabor ervas finas) }\end{array}$ \\
\hline $\begin{array}{l}\text { Proteína (N x 6,25) } \\
\text { Fibra alimentar }\end{array}$ & 8,1 & 9,3 & 9,2 & 9,2 \\
(total) & 2,0 & 2,2 & 2,2 & 1,7 \\
Lipídios (totais) & 15,6 & 15,8 & 15,8 & 15,7 \\
Cinzas & 1,9 & 2,0 & 2,2 & 2,3 \\
Umidade & 4,1 & 6,6 & 5,4 & 5,8 \\
Carboidrato & 68,3 & 64,1 & 65,4 & 65,3 \\
(diferença) & & & & \\
Energia & 446 & 436 & 440 & 439 \\
(kcal/100 g) & & & & \\
${ }^{1}$ Resultados são médias de 2 determinações (duplicata)
\end{tabular}

Na Tabela 4 é apresentada a composição em aminoácidos (essenciais e não essenciais) do biscoito de formulação padrão e do biscoito enriquecido com $5 \%$ de extrato (Ex) de levedura. Na mesma tabela, o perfil de aminoácidos essenciais dos dois tipos de biscoito é comparado com o perfil teórico da FAO/WHO [10], para crianças na faixa etária de 2 a 5 anos de idade.

TABELA 4. Composição de aminoácidos do biscoito de formulação padrão e de um biscoito enriquecido com $5 \%$ (p/p) de extrato (Ex) de levedura.

\begin{tabular}{|c|c|c|c|}
\hline $\begin{array}{l}\text { Aminoácido } \\
\text { (g/100 g Prot) }\end{array}$ & $\begin{array}{c}\text { Biscoito } \\
\text { formulação } \\
\text { padrão }\end{array}$ & $\begin{array}{c}\text { Biscoito } \\
\text { enriquecido } \\
(5 \% \mathrm{Ex})\end{array}$ & $\begin{array}{r}\text { Referência } \\
\text { (FAOMHO) }\end{array}$ \\
\hline \multicolumn{4}{|l|}{ Essenciais } \\
\hline Treonina & $2,5^{\star}$ & $2,8^{*}$ & 3,4 \\
\hline Metionina + cisteína & 2,5 & 2,8 & 2,5 \\
\hline Valina & 3,7 & 4,2 & 3,5 \\
\hline Leucina & 6,8 & 7,2 & 6,6 \\
\hline Isoleucina & 3,0 & 3,4 & 2,8 \\
\hline Fenilalanina + tirosina & 6,4 & 7,4 & 6,3 \\
\hline Lisina & $2,2^{\star \star}$ & $3,5^{\star \star}$ & 5,8 \\
\hline Histidina & 1,8 & 1,9 & 1,9 \\
\hline \multicolumn{4}{|l|}{ Não essenciais } \\
\hline Cisteína & 1,3 & 1,4 & \\
\hline Tirosina & 2,2 & 2,5 & \\
\hline Ácido aspártico & 3,9 & 5,2 & \\
\hline Ácido glutâmico & 36,0 & 34,2 & \\
\hline Serina & 4,8 & 5,0 & \\
\hline Prolina & 12,6 & 11,5 & \\
\hline Glicina & 3,8 & 4,1 & \\
\hline Alanina & 2,8 & 3,7 & \\
\hline Arginina & 2,5 & 3,3 & \\
\hline \multicolumn{4}{|l|}{ Escore de aminoácidos } \\
\hline essenciais (EAE \%) & 38,0 (Lys) & 60,0 (Lys) & \\
\hline
\end{tabular}


TABELA 5. Digestibilidade verdadeira da proteína (Dv\%) e quociente de utilização líquida da proteína (NPR), em ensaios com ratos tratados com dietas contendo $8 \%$ de proteínas das seguintes fontes: caseina (padrão), biscoito de formulação padrão (referência) e biscoito enriquecido com $5 \%$ de extrato (Ex) de levedura.

\begin{tabular}{lccc}
\multicolumn{1}{c}{ Tr atamento } & Dv (\%) & NPR & PDCAAS $^{1}$ \\
\hline Caseína & $96,3 \pm 0,6^{\mathrm{a}}$ & $3,6 \pm 0,3^{\mathrm{a}}$ & $82,3^{*}$ \\
Biscoito padrão & $93,7 \pm 2,8^{\mathrm{a}}$ & $1,0 \pm 0,2^{\mathrm{c}}$ & 35,6 \\
Biscoito enriquecido & $88,9 \pm 2,2^{\mathrm{b}}$ & $2,0 \pm 0,3^{\mathrm{b}}$ & 53,3
\end{tabular}

${ }^{1} \mathrm{PDCAAS} \%=\mathrm{EAE} \times \mathrm{Dv} \%$

* Valor da literatura: ZINSLY et al. [23]

Pelos dados da Tabela 4, pode-se observar que as deficiências em aminoácidos essenciais da farinha de trigo (biscoito padrão) são a treonina, representando $73 \%$ do recomendado e, principalmente, a lisina (38\% do recomendado). A adição de $5 \%$ de extrato de levedura diminuiu a limitação de treonina de cerca de $9 \%$ e o de lisina em $22 \%$. Mesmo após adição de $5 \%$ de Ex, a proteína do biscoito enriquecido continua com uma deficiência de $18 \%$ em treonina e $40 \%$ em lisina, o que poderia ter sido corrigido pela adição de uma certa quantidade de proteina de soja ou caseína.

O impacto nutricional da adição de 5\% Ex ao biscoito de formulação padrão pode ser apreciado com os dados da Tabela 5.

Com a adição do Ex, o índice de utilização liquida da proteína (NPR) se elevou de 1,0 para o biscoito padrão para 2,0 no biscoito enriquecido, uma melhoria de $100 \%$ no índice de utilização biológica da proteína do biscoito, significando que os animais alimentados com os biscoitos enriquecidos com o Ex, teriam suas necessidades protéicas satisfeitas com metade da proteína requerida pelos animais em dieta de biscoito padrão (referência).

Ainda na Tabela 4, introduziu-se o PDCAAS (digestibilidade verdadeira da proteína corrigida pelo escore de aminoácidos essenciais) que é o produto do EAE pela digestibilidade verdadeira, segundo HENLEY \& KUSTER [12]. Esse indice foi proposto nos Estados Unidos para rotulagem dos alimentos, em substituição ao PER (quociente de eficiência protéica), determinado experimentalmente. Pela análise dos dados de PDCAAS (Tabela 5), verifica-se que a melhoria do PDCAAS $(67 \%)$ foi inferior à melhora de $100 \%$ no NPR. Este fato mostra que o extrato de levedura estimulou o crescimento dos ratos não somente por meio da melhora do perfil de aminoácidos essenciais (EAE) do biscoito padrão, mas também por meio de fatores de crescimento presentes no extrato, que não são computados no cálculo do PDCAAS, mas que estão presentes no extrato de levedura [5, 7, 8, 14].

Por esse motivo, a substituição dos indices obtidos em ensaios biológicos, com base no crescimento, pelo PDCAAS, deve ser visto com cautela. Sempre que a fonte protéica que compor a dieta contiver um ou mais fatores de crescimento, o PDCAAS estará subestimando o valor da fonte protéica e da dieta em que ela estiver contida.
A avaliação sensorial foi feita em dois lotes de biscoitos, que receberam diferentes formulações.

$\mathrm{Na}$ Tabela 6 são apresentados os resultados dos testes de ordenação (preferência) para um biscoito de formulação padrão e biscoitos enriquecidos com $2,5 \%$ e $5 \%$ de extrato (Ex) ou 5\% de autolisado (AT) de levedura.

TABELA 6. Resultados dos testes de ordenação, quanto à preferência, de biscoitos padrão e enriquecidos com derivados de levedura.

\begin{tabular}{lc}
\multicolumn{1}{c}{ Amostra } & Ordenação* \\
Mais preferido & \\
Biscoitos com 2,5\% de Ex de levedura & $93,0^{\circ}$ \\
Biscoitos com 5\% de Ex de levedura & $115,0^{\mathrm{b}}$ \\
Biscoitos com 5\% de AT de levedura & $123,0^{\mathrm{b}}$ \\
Menos preferido & \\
Biscoitos de formulação padrão & $169,0^{\mathrm{a}}$
\end{tabular}

*Resultados representam a soma total da pontuação dada pelos provadores, segundo a ordem de preferência ( $1=$ mais preferido; $4=$ menos preferido)

a,b,c Resultados com letras sobrescritas diferentes diferem estatisticamente $(p<0,05)$

O biscoito de formulação padrão teve a menor preferência e diferiu das outras três formulações $(p<0,05)$. $O$ biscoito enriquecido com $2,5 \%$ de Ex teve a maior preferência dos provadores, porém, não diferiu $(p>0,05)$ do biscoito com $5 \%$ de Ex. O biscoito com $5 \%$ de autolisado (AT) não diferiu estatisticamente de $5 \%$ de Ex, porém, diferiu do biscoito com 2,5\% de Ex. É importante notar que as três formulações enriquecidas com derivados de levedura resultaram em biscoitos de maior preferência que o biscoito de formulação padrão, observando-se uma tendência de superioridade do Ex em relação ao AT, para esse tipo de produto.

As principais observações dos provadores em relação aos biscoitos foram: para o padrão; textura mole, pouco crocante, fraco com relação a aroma e sabor; para os biscoitos com Ex $(2,5$ e 5,0\%) os comentários mais comuns foram textura crocante, sabor e aroma agradáveis; para os biscoitos com $5 \%$ de AT, os comentários mais freqüentes foram crocante, boa textura e sabor agradável, tendo havido também comentários sobre sabor queimado e/ou amargo (12\%).

Como uma tentativa de melhorar ainda mais a aceitação dos biscoitos enriquecidos, decidiu-se pela adição de alguns saborizantes e aromatizantes na formulação, como extratos de "bacon", de ervas finas e de queijo.

Os resultados da avaliação sensorial pelos testes de ordenação (preferência) e de aceitabilidade (escala hedônica) para as novas formulações são apresentados na Tabela 7.

Pelos resultados dos testes de ordenação, o biscoito menos preferido foi o de formulação padrão, sem adição de extrato de levedura ou aroma, enquanto que o de maior aceitação foi o biscoito com $5 \%$ Ex mais $1,5 \%$ de aroma a "bacon". Os outros dois biscoitos, também com $5 \%$ de Ex, mas com $1 \%$ de aroma de ervas finas ou $0,75 \%$ de aroma de queijo, ficaram entre os dois extre- 
mos na escala de ordenação. Os biscoitos com aroma a "bacon" e os com aroma de ervas finas foram os que tiveram maior aceitação e diferiram estatisticamente $(p<0,05)$ dos de aroma de queijo e do biscoito padrão, que não diferiram entre si $(\mathrm{p}>0,05)$.

TABELA 7. Resultados obtidos no teste de ordenação quanto à preferência e aceitabilidade das amostras de biscoito de formulação padrão e enriquecidos com $5 \%$ de Ex de levedura.

\begin{tabular}{|c|c|c|}
\hline Amostra & Ordenação* & Aceitabilidade $^{\star \star}$ \\
\hline $\begin{array}{l}\text { Mais preferido: } \\
\text { Biscoito com } 5 \% \text { de extrato de } \\
\text { levedura e } 1,5 \% \text { de aroma de } \\
\text { bacon }\end{array}$ & $108,0^{c}$ & $6,8 \pm 2,1^{a}$ \\
\hline $\begin{array}{l}\text { Biscoito com } 5 \% \text { de extrato de } \\
\text { levedura e } 1 \% \text { de aroma de } \\
\text { ervas finas }\end{array}$ & $117,0^{\mathrm{b}, \mathrm{c}}$ & $6,9 \pm 1,9^{a}$ \\
\hline $\begin{array}{l}\text { Biscoito com } 5 \% \text { de extrato de } \\
\text { levedura e } 0,75 \% \text { de aroma de } \\
\text { queijo }\end{array}$ & $142,0^{a, b}$ & $6,3 \pm 2,0^{a}$ \\
\hline $\begin{array}{l}\text { Menos preferido: } \\
\text { Biscoito padrão (sem adição de } \\
\text { extrato de levedura ou aroma) }\end{array}$ & $153,0^{\mathrm{a}}$ & $6,1 \pm 1,7^{\mathrm{a}}$ \\
\hline
\end{tabular}

Não houve diferença estatística ( $p>0,05)$ na aceitabilidade dos vários tipos de biscoito testados, embora tendo-se confirmado a tendência de maior aceitação para os biscoitos com os aromas "bacon" e ervas finas, em detrimento do biscoito padrão e do biscoito enriquecido com aroma de queijo.

A Figura 1 ilustra claramente a freqüência dos niveis de aceitação manifestados pelos provadores, com base na escala hedônica, variando de gostei extremamente a desgostei extremamente. É interessante observar que para o biscoito de formulação padrão, as maiores freqüências de manifestação foram para gostei ligeiramente e gostei moderadamente, enquanto que para os biscoitos enriquecidos com $5 \%$ de Ex, particularmente os adicionados de sabor "bacon" e sabor ervas finas, as maiores freqüências de manifestação dos provadores foram para gostei muito e gostei extremamente.

Ao compararmos os resultados da análise sensorial realizada nos biscoitos produzidos a partir de dois lotes diferentes de derivados de levedura (Tabelas 6 e 7), podemos afirmar que a adição de 2,5 ou $5 \%$ de derivados de levedura (Ex ou AT) melhora significativamente as características sensoriais de aceitabilidade e preferência de biscoitos tipo água e sal, produzidos através de uma formulação padrão (Tabela 1). Podemos também inferir que o extrato de levedura conferiu aos biscoitos caracteristicas sensoriais ligeiramente superiores às do autolisado, embora não tivesse havido diferença estatística na comparação desses dois derivados, quando adicionados aos biscoitos.
É importante atinar para o fato de que o enriquecimento de biscoitos com o extrato de levedura, não somente melhorou de maneira significativa o valor protéico do produto, mas também as suas características sensoriais de aceitabilidade e preferência dos consumidores.

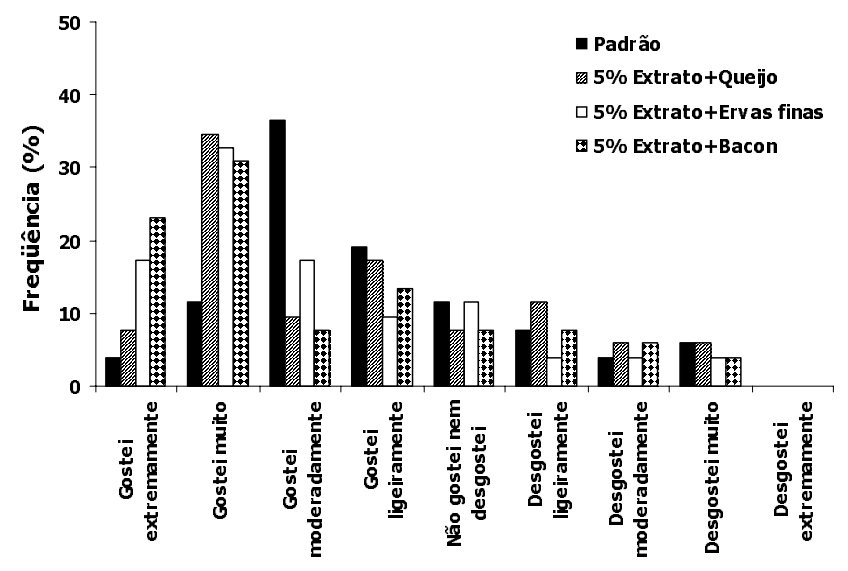

FIGURA 1. Representação gráfica das freqüências de respostas relativas à aceitabilidade de biscoitos de formulação padrão e biscoitos enriquecidos.

\section{4 - CONCLUSÕES}

Os resultados da análise química (composição centesimal, perfil de aminoácidos), avaliação nutricional (valor protéico) e testes de aceitabilidade e preferência do consumidor, permitiram concluir que a adição de $5 \%$ $(\mathrm{p} / \mathrm{p})$ de extrato ou autolisado de levedura à formulação padrão de biscoitos tipo água e sal melhorou não somente a composição e o valor protéico do produto final, mas também elevou a aceitação e a preferência do consumidor para esse tipo de produto.

\section{5 - REFERÊNCIAS BIBLIOGRÁFICAS}

[1] ANÔNIMO. Yeast and yeast derivatives application. Food Technology, Chicago, v. 41, n. 2, p. 122-125, 1987.

[2] A.O.A.C. - Association of Official Agricultural Chemists, Official Methods of Analysis, $16^{\text {th }}$ edition, Washington, D.C., 1998.

[3] ASP, N. G.; JOHANSSON, C.G.; HALMER, H.; SILJESTRÖM, M.A. A rapid enzymatic assay of insoluble and soluble dietary fiber. Journal of Agricultural and Food Chemistry, Washington, v. 31, n. 3, p. 476-482, 1983.

[4] BLIGH, E.G.; DYER, W.J. A rapid method of total lipid extraction and purification. Canadian Journal of Biochemistry and Physiology, Ottawa, v. 37, n. , p. 911-917, 1959.

[5] BRUNSER, O.; ESPINOZA, J.; ARAYA, M.; CRUCHET, S.; GIL, A. Effect of dietary nucleotide supplmentation on diarrhoea disease in infants. Acta Paediatrica, Oslo, v. 83, n. 2, p. 188-191, 1994.

[6] CAMERON, D.R.; COOPER, D.G.; NEUFELD, R.J. The mannoprotein of Saccharomyces cerevisiae is an effective bioemulsifier. Applied and Environmental Microbiology, Washington, v. 54, n. 6, p. 1420-1425, 1988. 
[7] CARVER, J.D. Dietary nucleotides: cellular immune, intestinal and hepatic system effects. Journal of Nutrition, Bethesda, v. 124, n. 1, p. 144S-148s, 1994.

[8] CARVER, J.D.; PIMENTEL, B.; COX, W.I.; BARNESS, L.A. Dietary nucleotides effects upon immune function in infants. Pediatrics, Madison, v. 88, n. 2, p. 359-363, 1991

[9] DZIEZAK, J.D. Yeast and yeast derivatives: definitions, characteristics and processing. Food Technology, Chicago, v. 41, n. 2, p. 103-121 and 122-125, 1987.

[10] F.A.O./W.H.O. - Food and Agriculture Organization/World Health Organization. Protein quality evaluation. Report of a joint FAO/WHO expert consultation, Food and Nutrition Paper, n. 51, Rome, 1989, 72p.

[11] HALÁSZ, A.; LASZTITY, R. Use of yeast biomass in food production. Boca Raton, CRC Press, 1991, 312p.

[12] HENLEY, E.C.; KUSTER, J.M. Protein quality evaluation by protein digestibility corrected amino acid scoring. Food Technology, Chicago, v. 48, n. 4, p. 74-77, 1994.

[13] HERBERT, D.; PHIPPS, P. J.; STRANGER, R.E. Chemical analysis of microbial cells. In: Norris, J.R., Ribbors, P. W. (Eds.) Methods of Enzymology, London, Academic Press, 1971, v. 5B.

[14] IDOTA, T.; KAWARAMI, H.; NAKAGIMA, I. Growth promoting effect of $\mathrm{N}$-acetylneuraminic acid substances on Bifidobacteria. Bioscience, Biotechnology and Biochemistry, Tokio, v. 58, n. 9, p. 1720-1722, 1994.

[15] KELLY, M. Yeast extract. In: Industrial Enzymology: The Application of Enzymes in Industry, Godfrey, T.; Reicheld, J. (Eds.). The Nature Press, N. York, 1983, p. 457-465.

[16] KINIGHT, S. Yeast protein enhances flavour and nutrition. Food Process, Kent, v. 55, n. 10, p. 1314, 1986.
[17] KOLLAR, R.; STURDUK, E.; SAJBIDOR, J. Complete fractionation of Saccharomyces cerevisiae biomass. Food Biotechnology, New York, v. 6, n. 3, 225-237, 1992.

[18] MEILGAARD, M.; CIVELLZ, G.V.; CARR, B.T. Sensory Evaluation Techniques. $3^{\text {rd }}$ edition, CRC Press, Inc., Boca Raton, FL, 1999. 387p.

[19] NEWMAN, K.E. Mannoligosaccharides and animal nutrition. In: Proceedings of the Alltech's $9^{\text {th }}$ Asia-Pacific Lecture Tour, v. 9, p. 55-60, 1995.

[20] NRC - National Research Council, Recommended Dietary Allowances (R.D.A.), $10^{\text {th }}$ Edition, Washington D.C.: National Academy Press, 1989, p. 24-38.

[21] REEVES, P. G.; NIELSEN, F.H.; FAHEY Jr., C.C. AIN-93 purified diet for laboratory rodents: final report on the American Institute of Nutrition ad hoc Committee on the reformulation of the AIN-76 ${ }^{\text {a }}$ rodent diet. Journal of Nutrition, Bethesda, v. , 123, n. 2, p. 467-472, 1993.

[22] SGARBIERI, V.C. Proteínas em alimentos protéicos: propriedades, degradações, modificações. Ed. Varela, São Paulo, 1996, 517p. , p. 375-376.

[23] ZINSLY, P. F.; SGARBIERI, V.C.; PEREIRA DIAS, N. F.G.; JACOBUCCI, H.B.; PACHECO, M.T.B.; BALDINI, V.L.S. Produção piloto de concentrados de proteínas de leite bovino: composição e valor nutritivo. Brazilian Journal of Food Technology, Campinas, v. 4, n. 1, p. 1-8, 2001 Índice de Kovats:

\section{6 - AGRADECIMENTOS}

Os autores agradecem à FAPESP (Fundação de Amparo à Pesquisa do Estado de São Paulo) pelo suporte financeiro a este projeto. Também à COPERSUCAR (Cooperativa dos Produtores de Açúcar e Álcool) pelo apoio técnico e financeiro. 